\title{
An Exploratory Study to Assess the Knowledge and Attitude of Staff Nurses Regarding Care of Unconscious Patients in Selected Hospitals of Pune City
}

\author{
Archala Khemnar \\ Bharati Vidypeeth Deemed University, Pune-43, Maharashtra, India
}

\begin{abstract}
An unconscious patient fully depends on nurses for his/ her recovery thus it is the nurse's responsibility to think criticall $y$ always before intervening. Therefore it is very important that every nurse working in such areas has enough knowledge and a positive attitude to assess and intervene appropriately. Keeping this in view an exploratory study is conducted. The study statement is "to assess the knowledge and attitude of staff nurses regarding care of unconscious patients in selected hospitals of Pune city." The objectives of the study were: 1 . To assess knowledge of staff nurses regarding care of unconscious patients. 2. To assess the attitude of staff nurses regarding care of unconscious patients. 3. To find correlation between knowledge with attitude of staff nurses regarding care of unconscious patients. 4. To find association between nurse's knowledge and attitude with selected demographic variables. A non probability convenient sampling technique was used for the study. Sample size was 200 staff nurses from the Medical ICU, Neuro ICU, Medical- surgical wards and Cardiac recovery. The theory adopted is Imogene Kings goal attainment theory as the theoretical base for the framework of the study. The content validity of the tool was done by experts from the field of nursing, clinical psychology, intensive care medicine, and surgery. The tool consisted of demographic profile, structured knowledge questionnaire and modified attitude scale. Data analysis was done by using both descriptive and inferential statistics. The major findings of the study were, Description of Knowledge score of nurses on care of unconscious patients proved that $63 \%$ of staff nurses have average knowledge score and $33.50 \%$ of staff nurses had good knowledge score regarding care of unconscious patients. Description of Attitude score of nurses on care of unconscious patient proved that $63 \%$ of staff nurses have highly positive attitude score and $37 \%$ of staff nurses have moderate positive attitude score. Description of Correlation between knowledge and attitude score of nurses on care of unconscious patients specified that increased knowledge score shows positive attitude score. Description of knowledge and attitude score on demographic variables showed that there is no association between the age of the staff nurse, total clinical experience and ICU experience with regards to knowledge regarding care of unconscious patients. The knowledge and attitude was slightly better in nurses who were having $>2$ years of experience but it was not statistically proven. Lastly there was noassociation between knowledge and frequency of care of unconscious patients. But nurses who cared weekly for unconscious patients showed more positive attitude.
\end{abstract}

Keywords: knowledge, attitude, staff nurses, unconscious

\section{Introduction}

\section{Background of the Study}

"Nursing is a process in which the nurses is temporarily the consciousness of the unconscious, the love of life for the suicidal, the leg of the amputee, the eyes for the newly blind, a means of locomotion for the infant, a mouthpiece for those too weak or withdrawn to speak. In short, she should enter into the skin of her patient"

Virginia Henderson

Nursing is a noble profession, it involves encounter with a patient and his attendant during which a nurse observes, supports, communicates, ministers, teaches and provides care during illness with an aim of assisting in achieving patients optimum health ${ }^{1}$

The basic nursing activities are carried out for giving care and comfort to the patient, and it should always be kept in mind that an unconscious patient fully depends on nurses for his or her recovery and it is the nurse's responsibility to think critically always before intervening, therefore it is very important that every nurse working in such areas has enough knowledge to assess and intervene There needs to be enough staff to monitor the patient closely, also proper supervision of a charge nurse is a must to make sure patient's gets quality care. Gaining more knowledge the nurses can bring about a great difference in their patient's life. Nurse's knowledge and attitude can make a miracle in quick recovery of the patients.

\section{Need of the Study}

Nurses have their own problems such as overwork, understaffed, double duties, lack of appreciation, low motivation all this affect their attitude towards nursing and patient care, inadequate physical structure for education and lack of clinical experience to students leads to incompetent future staff. ${ }^{2}$

Number of nurses is increasing but the quality is deteriorating. Clinical experience is becoming a rare commodity. Hence development of skills is difficult and therefore the new nurses with only knowledge and inadequate practice are not able to give effective care. ${ }^{3}$

And therefore the investigator felt it necessary to explore the knowledge and attitude of staff nurses regarding care of the patients who are unconscious due to any cause, because the unconscious patient fully depends on nursing care, and this is best way to assess the nursing practice. 


\section{International Journal of Science and Research (IJSR) \\ ISSN (Online): 2319-7064 \\ Index Copernicus Value (2013): 6.14 | Impact Factor (2015): 6.391}

\section{Statement of the Problem}

"An exploratory study to assess the knowledge and attitude of staff nurses regarding care of unconscious patients in selected hospitals of Pune city".

\section{Objectives of the Study}

1) To assess knowledge of staff nurses regarding care of unconscious patients.

2) To assess the attitude of staff nurses regarding care of unconscious patients

3) To correlate knowledge with attitude of staff nurses regarding care of unconscious patients.

4) To find association between nurse's knowledge and attitude with selected demographic variables.

\section{Assumptions}

The study assumes that:

1) Nurses play an important role in caring for unconscious patients.

2) Knowledge developed through education provides a sound basis for practice.

3) The knowledge of nurses regarding unconscious patient may influence their attitude towards care of the patient.

4) Nurses caring for unconscious patient may have some knowledge regarding care of unconscious patient.

\section{Criteria}

\section{Inclusion criteria}

1) Nurses who have completed General Nursing and Midwifery [G.N.M] or B.Sc Nursing [Basic or Post basic]

2) Nurses who render direct care to the patients.

3) Nurses who are interested in the study.

4) Nurses working with unconscious patients for a minimum period of two months.

\section{Conceptual Framework}

In the present study Imogene King's goal attainment theory was used as conceptual framework. She defined nursing as "A process of action, reaction and interaction and transaction by which nurse and client share information about their perception in nursing situation. Action is defined as a sequence of behaviors involving mental and physical action. Reaction which is considered as included in the sequence of behaviors described in action. The investigator plans to assess the knowledge and attitude of staff nurses caring for unconscious patients through the process of action , reaction, interaction and transaction phase. King's theory provides direction for nursing practice by emphasizing the processes of multidisciplinary collaboration, communication, interaction, transaction and use of critical thinking. ${ }^{4}$

Therefore the investigator found the kings goal attainment suitable for the present study.

\section{Review of Literature}

Dr. Jean Watson said, "Caring is transpersonal in nature, involving the one caring as well as the one being cared for."
With nurses so fraught with multiple demands and pressures, many lose touch with their caring mission.

A study done by P.Ravindran and A.K.Sood on knowledge of staff nurses about basic nursing care in a large hospital in Delhi, The knowledge in basic nursing care of 76 staff nurses posted in General and Specialty Wards of a large metropolitan city hospital has been assessed in this study, the results indicate that in four out of the five broad areas of basic nursing care for which knowledge was assessed; the nurses in either category of wards could not get 50 per cent score. Of these broad areas, the level of knowledge could be termed unsatisfactory, score less than 40 per cent, in the specific activities pertaining to suctioning, oxygen administration, postural drainage, bed positioning, and nursing action for accidental drug intake and in helping patient to communicate. The over-all total means score also indicates an unsatisfactory level of knowledge in basic nursing care for either category of nurses. However, there was no statistically significant difference was observed in the knowledge levels between the nurses of general and specialty wards. ${ }^{6}$

A descriptive study to assess the effectiveness of planned teaching programme on knowledge and attitude of nurses regarding sensory alterations in patients admitted in ICU of selected hospitals of Pune city" done by Mrs. Geeta Shiroor 2010,showed that the knowledge of nurses regarding sensory alterations in ICU patients before and after planned teaching programme proved that $66 \%$ of the nurses had poor Knowledge score regarding sensory alterations in patients admitted in ICU, before planned teaching programme. But there was significant increase in knowledge level of nurses after planned teaching programme regarding sensory alterations in patients admitted in ICU. 91\% of nurses had positive attitude regarding sensory alterations. Maximum nurses were showing positive attitude before planned teaching programme. But maximum nurses were showing strong positive attitude after planned teaching programme. Description of correlation between the knowledge and selected demographic variables proved that younger age group nurses and graduate nurses have higher knowledge score. Correlation with total experience and experience in ICU proved that there is no significant increase in knowledge even with increased years of experience. So total clinical experience and experience in ICU, indicates no significant relationship between the knowledge while professional qualification showed highly significant relationship between the knowledge of the nurses regarding sensory alterations in patients admitted in ICU. Description of association between attitude and selected demographic variables proved that age, professional qualification, total clinical experience and experience in ICU has no significant relationship between attitudes of the nurses regarding sensory alterations in patients admitted in ICU. Description of association between knowledge and attitude shows that there is positive correlation between Knowledge and attitude in pre-test. But the correlation between Knowledge and attitude in post-test is strongly positive. In both the cases correlation is positive and proves that increase in knowledge improves the attitude.

Lastly we have to accept the fact that nurses are there always to care for the patients, but it might as well not be if patients 


\section{International Journal of Science and Research (IJSR) \\ ISSN (Online): 2319-7064 \\ Index Copernicus Value (2013): 6.14 | Impact Factor (2015): 6.391}

and families don't see or feel it. That's why there's a crying need today to help nurses speak the language of caring so that their caring reaches the people they serve. In everyday routines, there are so many opportunities to make their caring felt and ease their patient's anxiety. For instance, when one nurse's shift is ending and another nurse is taking over the patient's care, the first nurse can ease the transition for the patient by speaking the language of caring during this important handoff. ${ }^{8}$

\section{Research Methodology}

Research approach used for the study is Quantitative research approach. The method adopted is exploratory method. The non experimental approach was considered to be appropriate to assess the knowledge and attitude of staff nurses regarding care of unconscious patients and the research design adopted is survey method. In this study, the population selected for the study comprised of the staff nurses who have completed GNM or B.Sc. nursing [Basic or Post basic] as their professional qualification. The study is conducted in the Medical ICU, Surgical ICU, Neuro-ICU, Cardiac Recovery, and Medical and Surgical wards of five private hospitals of Pune city Jehangir hospital ,N.M.Wadia hospital, Noble hospital ,Poona Hospital and Bharati hospital, samples are staff nurses working in selected hospitals of Pune city. And convenience sampling technique used was. In this study the sample consisted of 200 staff nurses.

\section{Data Collection Technique and Tool}

\section{Technique}

Structured questionnaire to assess knowledge and Likert scale to assess attitude was prepared.

Content validity for the Tool was done with the guidance of experts and the suggested changes were made.

\section{Reliability}

The reliability of the tool was established by using Rational Equivalence formula. Cronbach Alpha was used for reliability. The reliability of the tool was calculated to be $\mathbf{8 1 0 6}$ and $\mathbf{. 8 6 6 0}$ indicating degree of stability hence the items in the knowledge questionnaire and attitude scale was reliable and therefore retained.

\section{Pilot Study}

Pilot study is conducted in Jehangir hospital Pune. Twenty samples were selected by non-probability convenience sampling technique The data was analyzed and the result confirmed that the study is feasible and practicable.

\section{Analysis and Interpretation Of Data}

The collected data was tabulated, organized, analyzed and presented under the following headings:

Staff nurses taken for study were $39 \%$ in the age group of $23-25$ yrs. $19 \%$ were in $25-37$ yr of age $16.50 \%$ nurses were in the age group of $21-23$ yrs, $15.5 \%$ in the age group of 29 yrs and above and only $10 \%$ nurses were in the age group of 27- 29yrs.As per the qualification $63 \%$ (126) of nurses under study GNM and 37\% were with BSC Nursing. Based on clinical experience $62 \%$ of nurses had $>2$ years of total clinical experience and 38\% of nurses have $<2$ years of total clinical experience. However as regard to experience in ICU setup $59 \%$ of nurses had $<2$ yrs of experience and $41 \%$ of staff nurses had $>2$ yrs of ICU experience. With regard to nurses caring for unconscious patient on daily basis the percentage was $61.50 \%$ on weekly basis the percentage was $38.50 \%$.

Table 1: Description of Knowledge score of nurses on care of unconscious patients, $(\mathrm{N}=200)$

\begin{tabular}{|c|c|c|}
\hline Knowledge level grading & No of cases (f) & Percentage (\%) \\
\hline $0-8$ (Poor) & 7 & $3.50 \%$ \\
\hline $9-16$ (Average) & 126 & $63 \%$ \\
\hline $17-25$ (Good) & 67 & $33.50 \%$ \\
\hline Total & 200 & $100 \%$ \\
\hline
\end{tabular}

The data presented in Table 1 signifies that out of 200 staff nurses 3.50\%(7)of nurses showed poor knowledge score,63\%(126) of staff nurses showed average knowledge score and $33.50 \%(67)$ of staff nurses showed good knowledge score.

Table 2: Attitude score of nurses on care of Unconscious patients, $(\mathrm{N}=200)$

\begin{tabular}{|c|c|c|}
\hline Grading & No of cases(f) & Percentage (\%) \\
\hline $25-58$ ( Negative) & 0 & $0 \%$ \\
\hline $59-91$ (Positive) & 74 & $37 \%$ \\
\hline $92-125$ (Highly positive) & 126 & $63 \%$ \\
\hline Total & 200 & $100 \%$ \\
\hline
\end{tabular}

The data presented in Table 2 signifies that out of 200 staff nurses $0 \%$ of staff nurses had negative attitude score, $37 \%$ of staff nurses had positive attitude score and $63 \%$ of staff nurses have highly positive attitude score.

Table 3: Correlation between knowledge and Attitude score of nurses on care of unconscious patients .

\begin{tabular}{|l|l|l|}
\hline Correlation between & $r$ Value & $p$ Value \\
\hline Knowledge \& Attitude & 0.31 & $<0.0001$ \\
\hline
\end{tabular}

The above table indicated that there is a significant positive correlation between knowledge and attitude score of staff nurses on care of unconscious patients. As the p value is < 0.0001 .

The findings suggested that there is no significant difference between Knowledge and attitude score of nurses on care of unconscious patients according to age of nurses. As indicated by $\mathrm{p}$ value $>0.05$

There is no significant difference between the educational qualification and the knowledge of staff nurses but a significant difference is seen in attitude score.

There is no significant difference between the Total experience of nurses, ICU experience and frequency of caring for unconscious patients on the Knowledge score of nurses regarding care of unconscious patients. But where attitude is concerned significant difference is seen as evident by $\mathrm{p}$ value $<0.05$. This indicated nurses who cared weekly for an unconscious patient had better attitude score.

\section{Volume 5 Issue 4, April 2016




\section{International Journal of Science and Research (IJSR) \\ ISSN (Online): 2319-7064}

Index Copernicus Value (2013): 6.14 | Impact Factor (2015): 6.391

\section{Summary and Discussion}

The purpose of the study was to assess the knowledge and attitude of staff nurses regarding care of unconscious patients in selected hospitals of Pune city.

The Objectives of the study were,

1) To assess knowledge of staff nurses regarding care of unconscious patients.

2) To assess the attitude of staff nurses regarding care of unconscious patients.

3) To find correlation between knowledge with attitude of staff nurses regarding care of unconscious patients.

4) To find association between nurse's knowledge and attitude with selected demographic variables.

So after the analysis

1) Nurses had average knowledge regarding care of unconscious patients.

2) Both GNM and BSC Nurses were equal in their knowledge score but attitude score was more positive in the GNM nurses.

3) Age, total years of experience and ICU Experience had no association with knowledge and attitude regarding care of unconscious patients.

4) Knowledge is correlated to attitude. If knowledge of nurses increases the attitude also improves.

5) Nurses who cared weekly for unconscious patients had positive attitude score than nurses who cared daily.

A.P.J Abdul Kalam when asked to speak about nurses on nurse's Day said the following words

"When I see Nurses, I am reminded of angels moving in a full moon light" Meaning nurses work day and night with a smile on their faces.

\section{References}

[1] Sr.Daya Thomas "A study to assess the effectiveness of planned teaching programme for nurses working in ICU on communication with unconscious patients.Msc (Dissertation) St John's Medical College Banglore.2006.

[2] Health Action April 2011 pg no.7-10, 20,25

[3] Dagfinn Nåden, Katie Eriksson, Understanding the Importance of Values and Moral Attitudes in Nursing Care in Preserving Human Dignity, http://nsq.sagepub.com/content/17/1/86.abstract

[4] Imogene kings theory of goal attainment [on Line] http://currentnursing.com/nursing- Theory/goalattainment-theory.html.

[5] Yvonne.S etal Advance Directives and End of life Decision making survey of critical care nurses Knowledge, Attitude and experience.

[6] P.Ravindran A.K.Sood. A study on knowledge of staff nurses about basic nursing care in a large hospital in Delhi. Health and population -perspectives and issues 18(4):214-221, 1995.

[7] Geeta Shiroor. "Effectiveness of planned teaching programme on knowledge and attitude of nurses regarding sensory alterations in patients admitted in ICU of selected hospitals of Pune city" Bharati Vidyapeeth college of nursing, 2010- 2011, Pune, pg 80-94.
[8] Bibudha Bijayalaxmi, Acharya Urmila Pattanayak Siba Prasad. Knowledge of Staff Nurses Regarding Intravenous Catheter Related Infection Working in Orissa. The nursing journal of India, June 2010 VOL.Cl No.6

[9] Weendy Leebov's. American Nurse Today, [on line]http://www.quality-patient- experience.com/nursepatient-relationship.html

\section{Author Profile}

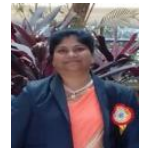

Archala Ganesh Khemnar received the Post Basic Bsc nursing through IGNOU, and MSc Nursing through Bharati Vidyapeeth deemed university Pune in2007 and 2012respectively. Presently she is working in Bharati Vidyapeeth school of nursing, Pune as a nursing Tutor. 